\title{
Does topical rifampicin reduce the risk of surgical field infection in hernia repair?
}

\author{
Şahin Kahramanca ${ }^{1}$, Oskay Kaya ${ }^{1}$, Cem Azılı', Bahadır Celep², Emre Gökce ${ }^{1}$, Tevfik Küçükpınar ${ }^{1}$
}

\section{ABSTRACT}

'Department of General Surgery, Dışkapı Yıldırım Beyazıt Teaching Hospital, Ankara, Turkey

2Department of General Surgery, Afyon Kocatepe University Faculty of Medicine, Afyon, Turkey

\section{Address for Correspondence} Dr. Şahin Kahramanca

Department of General Surgery, Dışkapı Yıldırım Beyazıt Teaching Hospital, Ankara, Turkey Phone.: +90 5314298484 e-mail: drkahramancasahin@gmail.com

Received: 10.05 .2013

Accepted: 30.05.2013

CCopyright 2013 by Turkish Surgical Association

Available online at www.ulusalcerrahidergisi.org
Objective: Inguinal hernia operations are common procedures in general surgery. There have been many approaches in the historical development of hernia repair; tension free repair with mesh being the most commonly used technique today. Although it is a clean wound, antibiotic use is still controversial due to concerns about infection related to synthetic mesh. We aimed to determine the probable role of topical rifampicin in patients with tensionfree hernia repair and mesh support.

Material and Methods: The charts of patients who underwent tension-free inguinal hernia repair were retrospectively analyzed. Information and operative notes on patients, in whom synthetic materials were used, were identified. The patients were divided into two groups, placebo group (G1) and patients with application of topical rifampicin on the mesh (G2). Infection rates between the groups in the early postoperative period were compared.

Results: The mean age of the 278 patients who were included in the study was $49.6 \pm 15.39$ and the female/male ratio was $10 / 268$. There were recurrent hernias in four patients and superficial wound infections in 22 patients in the early period. One patient had testicle torsion and underwent an orchiectomy. There were no significant differences between the groups in terms of age and gender. The types of hernia and body mass index were homogenous between the two groups. In the early postoperative period the infection rates were 16/144 (11.1\%) and 6/134 (4.48\%) in the groups, respectively, with the difference being statistically significant $(p=0.041)$.

Conclusion: We suggest that applying rifampicin locally can decrease surgical site infection in hernia operations where meshes are used.

Key Words: Inguinal hernia, rifampicin, surgical site infection

\section{INTRODUCTION}

The first written document about hernia repair dates back to Ebers papirus by Egyptians. Modern hernia repair, which began with Bassini, evolved with Shouldice, Stoppa and Lichtenstein, still being an area of investigation. The Lichtenstein tension-free hernia repair gained broad acceptance especially in the last decade due to its being an easily applied technique with low recurrence rates (1). However the polypropylene mesh used in this technique has given rise to complications like foreign body reaction, "Surgical Site Infection (SSI)", seroma, adhesion, graft migration, graft rejection and chronic pain (2-4). All these probable complications result in an increase in morbidity, length of hospital stay and cost. Glassow (5) reported that postoperative wound infection increases the recurrence rate by four fold, in his series of nearly 26000 cases. Although this is a clean wound there are data in the literature stating that prophylactic antibiotic use might be beneficial in patients with hernia repairs by using synthetic material, there are also publications concluding that this does not decrease the rate of infection $(1,6,7)$. We aimed to compare the infection rates between the group where antibiotic was not used with the group receiving intraoperative topical rifampicin over the mesh, in patients who underwent tension free inguinal hernia repair, thus aiming to assess the effect of topical antibiotic application on postoperative infection rates.

\section{MATERIAL AND METHODS}

An ethical board approval was obtained from Ankara Dışkapı Yıldırım Beyazıt Teaching Hospital on 17.12.2012, with the number of 06/03. The charts of all patients who underwent inguinal hernia repair during the period Jan 2010-September 2012 in our general surgery clinic were retrieved. The search revealed 367 patients. Data on age, gender, emergent/elective operations, medical illnesses, body mass index (BMI), primary/recurrent hernia, type of surgical technique, antibiotic protocol in patients with mesh, presence of surgical drain, postoperative seroma, culture results in case of infection within the first month, length of follow-up and recurrence rates were extracted. Patients under the age of 18 , history of emergency operations for irreductable hernia, presence of Diabetes Mellitus (DM) or immune, rheumatologic or immunosuppressive disease or received immunosuppressant treatment, receiving 
antibiotic therapy for local or systemic infection, using anticoagulants or oral contraceptives, anatomic repair, patients lost to follow-up were excluded, after exclusion of 89 such cases the study group contained 278 patients. Patients aged 65 or older were classified as the geriatric population (GP). The surgical site was shaved with an electrical shaver 30 minutes prior to the operation. The cleaning was done by $10 \%$ povidone iodide. The 278 study patients were divide into two groups according to their antibiotic use; 144 patients who did not receive any prophylactic systemic antibiotics constituted Group 1, 134 patients who received $250 \mathrm{mg}$ topical Rifampicin over the mesh based on surgeon's preference constituted Group 2. The follow-up duration was 6-36 months. The presence of infection was verified by obtaining cultures in case of detection of at least one of the signs: warmness, swelling, fluctuation, and redness by a general surgeon within the same clinic the patient was operated.

\section{Statistical Analysis}

The analysis was done by Statistical Packages for the Social Sciences (SPSS) Windows 17. The distribution of continuous variables was evaluated by Shapiro Wilk test. Descriptive statistics were shown as mean \pm standard deviation or median for continuous variables and as case numbers and percentage for categorical variables.

Intergroup difference in means was compared by Student's t test and in median with Mann-Whitney U test. Categorical variables were analyzed with Pearson'sChi-Square test. $\mathrm{P}<0.05$ was accepted as statistically significant.

\section{RESULTS}

The mean age of patients was $49.6 \pm 15.39$, the youngest patient was 18 and the oldest 84 . Female/male ratio was 10/268. Sixteen patients had recurrent hernias whereas 262 were primary cases. Polypropylene mesh was applied in all patients. A 7F Jackson Pratt drain was used in 30 patients to check hemorrhage. They were evaluated in an out-patient basis weekly for the first month and every 6 months thereafter for 6-36 months, with a mean duration of $19.20 \pm 8.75$ months. Four patients developed recurrences, 22 patients infection within the first month and one patient underwent orchiectomy for testicular torsion.

The gender distribution was similar in Group 1 and Group $2 ; 3 / 141(2.13 \%)$ and $7 / 127(5.51 \%)$ respectively $(p=0.16)$. The mean age was homogenous in the groups, in Group 1 $50.82 \pm 15.23$, and in Group $248.28 \pm 15.50(p=0.17)$. The study included 55 geriatric patients that did not show any difference in the two groups $(p=0.17)$. Group 1 included 7 recurrent cases and 137 primary inguinal hernia; and Group 2 included 9 recurrent cases and 125 primary inguinal hernia, no significant difference was shown $(p=0.51)$. BMl in the groups were $25.41 \pm 2.56$ and $26.28 \pm 3.30$ respectively, and it was not statistically significant $(p=0.11)$. Group 1 had 14 patients and Group 2 had 16 with drain placement, this showed no statistical significance $(p=0.55)$.

The mean follow-up duration was $20.08 \pm 9.27$ months in Group 1, and 18.25 \pm 8.1 months in Group 2 and the two groups did not show any statistical significance $(p=0.10)$. During the first postoperative month the infection rates in the groups were $16 / 144(11.1 \%)$ and $6 / 134(4.48 \%)$ respectively, and the difference was statistically significant $(p=0.04)$. When infection rates in patients who belong to the geriatric population were compared to the remaining population the SSI rate for GP was $9 / 55$ (16.36\%), in contrast to the rate of $13 / 223(5.83 \%)$ in patients who were not in the GP and the infection rate in the geriatric population was statistically higher $(p=0.01)$. In patients with suspicion of infection a suture was taken out and the incision was cultured by a swab. The culture results revealed Staph. aureus in 14 patients, and Staph. epidermidis in 8 patients. All these patients had superficial infections, none of them required major drainage. In the postoperative period 15 patients developed seroma or hematoma, 8were minimal superficial and 7 were deep hematomas that required drainage. Seroma and hematoma formation did not show any significant difference between the two groups $(p=0.89)$. In the follow-up period of 6-36 months, recurrence rates were similar between the groups $(p=0.28)$. Table 1 lists demographic and statistical data. None of the patients exhibited any allergic reactions after application of topical rifampicin.

\section{DISCUSSION}

Inguinal hernia repair is one of the most common operations in general surgery (6). The common goal in all techniques is providing an acceptable recurrence rate with minimum morbidity. One of the main complications of hernia operations is SSI, and since 1964, a uniform SSI classification is being used. Currently, surgical wounds are classified as clean, clean contaminated, contaminated and dirty-infected wounds (6). Clean wounds contain procedures unrelated to the gastrointestinal, urogenital and respiratory systems and theoretically, since the operation is carried out under sterile conditions they are protected from infection. Elective hernia surgery is an example of clean wounds and requirement of antibiotic coverage is controversial. In techniques like Lichtenstein tension free anterior mesh hernia repair, which became a routine operation since the 1980's, synthetic materials are used. It is suggested that these grafts may result in infectious complications; therefore, studies have emerged regarding the use of antibiotics $(1,6)$.

Simchen et al. (8) reported an SSI rate of 3.3\% in their series of 1138 inguinal hernia repairs, whereas Medina et al published a rate of (9) 7\%, and Santos et al. (10) found this rate to be $14.04 \%$. The wide range present in the literature is thought to arise from variations in surgical technique, contamination from the skin flora and antibiotic prophylaxis. Our infection rate was evaluated as $7.9 \%(22 / 278)$, parallel to the literature.

Sanchez et al. published a Cochrane meta-analysis (11) in 2003 , including 8 prospective randomized studies. They stated that in six studies antibiotic prophylaxis was show not to be helpful, whereas in two studies antibiotic prophylaxis had an effect on decreasing SSI rates (1, 12-17). However, three of the included studies did not use synthetic materials, thus surgical technique was not homogenous within the meta-analysis, making it hard to draw reliable results. 
Platt et al. (12), concluded that prophylactic antibiotics are helpful in lowering infection rates in their prospective randomized double-blind study of 612 cases, where they applied 1 gram intravenous cefonicid. Their infection rates in 6 weeks was decreased from $4.2 \%$ to $2.3 \%$ in the study group, with a decrease of 1,9\%. Lazorthes et al. (17)used 750 mg cefamandol together with subcutaneous local anesthesia in 155 patients with hernia repair, and in the early period they did not encounter any SSI in this group as compared to $4.5 \% \mathrm{SSI}$ in their control group of 153 patients, and the decrease in SSI by antibiotics was statistically significant $(p=0.01)$. Taylor et al. (7)

Table 1. Demographic data and statistical analysis between the groups

\begin{tabular}{|c|c|c|c|}
\hline & Group 1 & Group 2 & $\begin{array}{c}\text { Statistical } \\
\text { analysis }\end{array}$ \\
\hline Patient No & 144 & 134 & \\
\hline $\begin{array}{l}\text { Age } \\
\text { (mean years) }\end{array}$ & $50.82 \pm 15.23$ & $48.28 \pm 15.50$ & $p=0.17$ \\
\hline $\begin{array}{l}\text { Geriatric } \\
\text { population }\end{array}$ & $33 / 144$ (22.9\%) & $22 / 134$ (16.4\%) & $p=0.17$ \\
\hline Gender (Female/Male) & $3 / 141(2.13 \%)$ & $7 / 127$ (5.51\%) & $p=0.16$ \\
\hline $\begin{array}{l}\text { Hernia Type (Primary/ } \\
\text { Recurrence) }\end{array}$ & $137 / 7$ & $125 / 9$ & $p=0.51$ \\
\hline BMI & $25.41 \pm 2.56$ & $26.28 \pm 3.30$ & $p=0.11$ \\
\hline Presence of drains & $14 / 144(9.72 \%)$ & 16/134 (11.94\%) & $p=0.55$ \\
\hline Presence of seroma & 8/144 (5.56\%) & 7/134 (5.22\%) & $\mathrm{p}=0.89$ \\
\hline $\begin{array}{l}\text { Postoperative } \\
\text { infection }\end{array}$ & $16 / 144(11.1 \%)$ & $6 / 134(4.48 \%)$ & $p=0.04$ \\
\hline Positive culture (SA/SE) & $10 / 6$ & $4 / 2$ & $\mathrm{p}=0.83$ \\
\hline Follow up (months) & $20.08 \pm 9.27$ & $18.25 \pm 8.1$ & $p=0.28$ \\
\hline $\begin{array}{l}\text { Postoperative } \\
\text { recurrence }\end{array}$ & $1 / 144(0.69 \%)$ & $3 / 134$ (2.24\%) & $p=0.28$ \\
\hline
\end{tabular}

used co-amoxcylline prophylaxis with a follow-up of 1 month, found that the $\mathrm{SSI}$ rate was $8.8 \%$ vs. $8.9 \%$ in the placebo group, and suggested that antibiotic coverage is useless in elective inguinal hernia surgery. Yerdel et al. (1) published their prospective randomized series of 136 patients who were treated with tension-free hernia repair with polypropylene materials. They applied $1.5 \mathrm{gr}$ ampicillin-sulbactam and in a follow-up period of 4- 6 weeks the SSI rate was $0.7 \%$ in the study group as compared to $9 \%$ in the placebo group. They concluded that although inguinal hernia surgery with synthetic materials falls into the category of clean wounds, the significant decrease in SSI showed the requirement for prophylactic antibiotic use. Aufenacker et al. (18) reported similar SSI rates in patients after hernia repair in 3 months follow-up in the placebo group and the group treated with cefuroxim axetil. Celdran et al. (19) found no SSI in 2 years follow-up in the group receiving cefazolin sodium prophylaxis whereas this rate was $8.2 \%$ in the non-prophylaxis group, and concluded that in patients undergoing hernia repair with synthetic materials prophylactic antibiotic use is useful. Gervino et al. (20) reported an SSI rate of $0 \%$ out of 1181 patients in whom prophylactic $2 \mathrm{~g}$ ceftriaxon was used and they opted for antibiotic prophylaxis. Table 2 summarizes the reference studies regarding prophylactic antibiotic use. Similarly, in this study the infection rate in the group that antibiotics was not used was $11.1 \%$ whereas this rate was $4.48 \%$ in the group receiving local rifampicin application, and this difference was statistically significant $(p=0.04)$.

The pathogens causing SSI in elective hernia surgery usually are contaminations from the skin. The most common organisms detected in SSI are part of the skin flora, S. aureus and S. epidermidis. Yerdel et al. (1) isolated nine S. aureus, one S. epidermidis out of 13 patients with signs of infection, no bacterial agent was identified in 3 patients (1). Aufenacker et al. (18) series included S. aureus (35.3\%), no identification (29.4\%), mixed microorganisms (11.8\%) and other microorganisms (23.5\%). In our series similar to the literature, we isolated 14 S. aureus and 8 S. epidermidis in cultures.

Table 2. Infection rates in studies with prophylactic antibiotic coverage in hernia repair

\begin{tabular}{|c|c|c|c|c|c|}
\hline Authors & Number of patients & Follow-up period & \multicolumn{2}{|l|}{ Antibiotic prophylaxis } & Wound infection rates \\
\hline \multirow{2}{*}{ Platt et al. (11) } & 301 & \multirow{2}{*}{ 4-6 weeks } & \multirow{2}{*}{ Cefonicid } & + & $2.3 \%$ \\
\hline & 311 & & & - & $4.2 \%$ \\
\hline \multirow{2}{*}{ Lazorthes et al. (17) } & 155 & \multirow{2}{*}{4 weeks } & \multirow{2}{*}{ Cefamandol } & + & $0 \%$ \\
\hline & 153 & & & - & $4.5 \%$ \\
\hline \multirow{2}{*}{ Taylor et al. (12) } & & \multirow{2}{*}{ 4-6 weeks } & \multirow{2}{*}{ Co-amoxilav } & + & $8.8 \%$ \\
\hline & 280 & & & - & $8.9 \%$ \\
\hline \multirow[t]{2}{*}{ Yerdel et al. (1) } & 136 & \multirow[t]{2}{*}{4 weeks } & \multirow[t]{2}{*}{ Ampisillin-sulbactam } & + & $0.7 \%$ \\
\hline & 133 & & & - & $9 \%$ \\
\hline \multirow{2}{*}{ Aufenacker et al. (18) } & 503 & \multirow{2}{*}{12 weeks } & \multirow{2}{*}{ Cefuroxime Axetil } & + & $1.6 \%$ \\
\hline & 505 & & & - & $1.8 \%$ \\
\hline \multirow{2}{*}{ Celdran et al. (19) } & 50 & \multirow{2}{*}{104 weeks } & \multirow{2}{*}{ Cefazolin Sodium } & + & $0 \%$ \\
\hline & 49 & & & - & $8.2 \%$ \\
\hline Gervino et al. (20) & 1181 & 4 weeks & Ceftriaxon & + & $0 \%$ \\
\hline
\end{tabular}


The data on the use of topical antibiotics to prevent surgical site infections and to treat infections is limited. Rifampicin is a semi-synthetic antibiotic that has strong bactericidal effects on many Gram+ and - bacteria including S. aureus as well as tuberculosis treatment, with limited information on its topical use for wound care (21). Saydam et al. (22) argued that rifampicin and nitrofurazon combination is cheap and effective on $S$. aureus and S. epidermidis for full thickness wound care in their experimental study, although clinical studies are lacking. Iselin et al. (23) stated that rifampicin is superior to povidone iodide for infection control in extremity injuries. Weber et al. (24) reported a decrease in catheter related infection risk in children in case of minoxylline/rifampicin coated catheter use. There are some reports on the anaphylactic reactions following topical rifampicin use (25, 26). We have not encountered any allergic reactions in 134 patients receiving topical rifampicin.

\section{CONCLUSION}

There are few clinical studies in the literature that focus on topical antibiotic use on synthetic materials. We believe that the application of topical antibiotics is beneficial for prevention of infections, despite the fact that tension free inguinal hernia repair with mesh is accepted as a clean wound.

Ethics Committee Approval: Ethics committee approval was received for this study from the ethics committee of Dışkapı Yıldırım Beyazıt Training and Research Hospital (17.12.2012, 06/03).

Informed Consent: Written informed consent was obtained from patients who participated in this study.

Peer-review: Externally peer-reviewed.

Author Contributions: Concept - Ş.K.; Design - B.C., O.K.; Supervision S..K., T.K.; Funding - T.K.; Data Collection and/or Processing - E.G., C.A., B.C.; Analysis and/or Interpretation - T.K., Ş.K.; Literature Review - E.G., C.A.; Writer - Ş.K., T.K., O.K.; Critical Review - O.K., C.A., B.C.

Conflict of Interest: No conflict of interest was declared by the authors.

Financial Disclosure: The authors declared that this study has received no financial support.

\section{REFERENCES}

1. Yerdel MA, Akin EB, Dolalan S, Turkcapar AG, Pehlivan M, Gecim IE, et al. Effect of single-dose prophylactic ampicillin and sulbactam on wound infection after tension-free inguinal hernia repair with polypropylene mesh: the randomized, double-blind, prospective trial. Ann Surg 2001; 233: 26-33. [CrossRef]

2. Çakmak A. Inguinal greft infections. ANKEM Derg 2011; 25: 150153.

3. Li JF, Lai DD, Zhang XD, Zhang AM, Sun KX, Luo HG, et al. Metaanalysis of the effectiveness of prophylactic antibiotics in the prevention of postoperative complications after tension-free hernioplasty. Can J Surg 2012; 55: 27-32.

4. Sanabria A, Domínguez LC, Valdivieso E, Gómez G. Prophylactic antibiotics for mesh inguinal hernioplasty: a meta-analysis. Ann Surg 2007; 245: 392-396. [CrossRef]

5. Glassow F. Is postoperative wound infection following simple inguinal herniorraphy a predisposing cause for recurrent hernia? Can J Surg 1964; 91: 870-871.
6. Terzi C, Güler S. Is antibiotic prophylaxis necessary in inguinal hernia repair? Ulusal Cerrahi Dergisi 2005; 21: 169-174.

7. Taylor EW, Byrne DJ, Leaper DJ, Karran SJ, Browne MK, Mitchell KJ. Antibiotic prophylaxis and open groin hernia repair. World J Surg 1997; 21: 811-815. [CrossRef]

8. Simchen E, Rozin R, Wax $Y$. The Israeli study of surgical infection of drains and the risk of wound infection in operations for hernia. Surg Gynecol Obstet 1990; 170: 331-337.

9. Medina M, Sillero M, Martínez-Gallego G, Delgado-Rodríguez M. Risk factors of surgical wound infection in patients undergoing herniorrhaphy. Eur J Surg 1997; 163: 191-198.

10. Santos KRN, Neto GPB, Fonseca LS, Filho PPG. Incidence surveillance of wound infection in hernia surgery during hospitalization and after discharge in a university hospital. J Hosp Infect 1997; 36: 229-233. [CrossRef]

11. Sanchez-Manuel FJ, Seco-Gil JL. Antibiotic prophylaxis for hernia repair. The Cochrane database of Systemic Reviews; John Wiley \& Sons 2004.

12. Platt R, Zaleznik DF, Hopkins CC, Dellinger EP, Karchmer AW, Bryan $\mathrm{CS}$, et al. Perioperative antibiotic prophylaxis for herniorrhaphy and breast surgery. N Engl J Med 1990; 322: 153-160. [CrossRef]

13. Andersen JR, Burcharth F, Larsen HW, Røder O, Andersen B. Polyglycolic acid, silk, and topical ampicillin. Their use in hernia repair and cholecystectomy. Arch Surg 1980; 115: 293-295. [CrossRef]

14. Evans $C$, Pollock AV. The reduction of surgical wound infections by prophylactic parenteral cephaloridine. A controlled clinical trial. Br J Surg 1973; 60: 434-437. [CrossRef]

15. Morales R, Carmona A, Paga'n A. Utilidad de la profilaxis antibio'tica en la reducción de la infección de herida en la reparación de la hernia inguinal o crural mediante malla de prolipropileno [utility of antibiotic prophylaxis in reducing wound infection in inguinal or femoral hernia repair using polypropylene mesh]. Cir Esp 2000; 67: 51-59.

16. Otezia F, Ciga MA, Ortiz H. Profilaxis antibio'tica en la hernioplastia inguinal [antibiotic prophylax $\neg$ is in inguinal hernioplasty]. Cir Esp 2004; 75: 69-71. [CrossRef]

17. Lazorthes F, Chiotasso P, Massip P, Materre JP, Sarkissian M. Local antibiotic prophylaxis in inguinal hernia repair. Surg Gynecol Obstet 1992; 175: 569-570.

18. Aufenacker TJ, van Geldere D, van Mesdag T, Bossers AN, Dekker $B$, Scheijde E, et al. The role of antibiotic prophylaxis in prevention of wound infection after Lichtenstein open mesh repair of primary inguinal hernia: a multicenter double-blind randomized controlled trial. Ann Surg 2004; 240: 955-961. [CrossRef]

19. Celdrán A, Frieyro O, de la Pinta JC, Souto JL, Esteban J, Rubio JM, et al. The role of antibiotic prophylaxis on wound infection after mesh hernia repair under local anesthesia on an ambulatory basis. Hernia 2004; 8: 20-22. [CrossRef]

20. Gervino L, Cangioni G, Renzi F. A retrospective study on the efficiacy of short-term perioperative prophylaxis in abdominal surgery for hernia repair in 1254 patients. J Chemother 2000; 12: 34-7.

21. Hoover WW, Gerlach EH, Hoban DJ, Eliopoulos GM, Pfaller MA, Jones RN. Antimicrobial activity and spectrum of rifaximin, a new topical rifamycin derivative. Diagn Microbiol Infect Dis 1993; 16: 111-118. [CrossRef]

22. Saydam IM, YIImaz S, Seven E. The effect of nitrofurasone and rifampycine on full thickness wound healing. C. Ü. Tıp Fakültesi Dergisi 2005; 27: 113-120.

23. Iselin F, Audren JL, Gouet O, Hautefort E, Peze W, Pradet G. [Comparative study of the effects of a local antibiotic and a local antiseptic in emergency hand surgery]. Ann Chir Main Memb Super 1990; 9: 65-71. [CrossRef] 
24. Weber JM, Sheridan RL, Fagan S, Ryan CM, Pasternack MS, Tompkins RG. Incidence of catheter-associated bloodstream infection after introduction of minocycline and rifampin antimicrobial-coated catheters in a pediatric burn population. J Burn Care Res 2012; 33: 539-543. [CrossRef]
25. Erel F, Karaayvaz M, Deveci M, Ozangüç N. Severe anaphylaxis from rifamycin SV. Ann Allergy Asthma Immunol 1998; 81: 257-260. [CrossRef]

26. García F, Blanco J, Carretero P, Herrero D, Juste S, Garcés M, et al. Anaphylactic reactions to topical rifamycin. Allergy 1999; 54: 527-528. [CrossRef] 